\title{
DESENVOLVIMENTO DO FRUTO DA LICHIEIRA (Litchi chinensis Sonn.) 'BENGAL'1
}

\author{
LUIZ CARLOS CHAMHUM SALOMÃO², DALMO LOPES DE SIQUEIRA², MARCIO EDUARDO CANTO PEREIRA ${ }^{3}$
}

RESUMO - Estudou-se o desenvolvimento do fruto da lichieira (Litchi chinensis Sonn.) ‘Bengal'. Realizaram-se amostragens semanais, com início aos 35 dias após a antese e término no início da senescência dos frutos. A partir do 77ํ dia após a antese, os frutos foram decompostos em pericarpo, semente e arilo. A antese ocorreu na primeira semana de setembro. Foram ajustados modelos sigmoidais simples para acúmulo de matéria seca, comprimento e diâmetro. Para o acúmulo de matéria seca, uma fase inicial, de crescimento lento, prolongou-se até o 63ํ dia após a antese e coincidiu com um período de intensa queda natural de frutos. Do 63ํa a 98ํ dia após a antese, houve uma fase de rápido acúmulo de matéria seca. Até o $77^{0}$ dia, pericarpo e semente foram os principais responsáveis pelo acúmulo de matéria seca. Oitenta e oito por cento do comprimento e $65 \%$ do diâmetro máximos foram atingidos nesse período. Do $84^{0}$ ao $98^{0}$ dia após a antese, o desenvolvimento do fruto foi determinado basicamente pelo arilo. As dimensões e a matéria seca do fruto estabilizaram-se a partir do 98임 após a antese. O ponto de colheita comercial dos frutos, caracterizado pela coloração avermelhada do pericarpo, ocorreu a partir do $112^{0}$ dia após a antese. Verificou-se um quadro senescente nos frutos a partir do $119^{0}$ dia após a antese.

Termos para indexação: Litchi chinensis, inflorescência, fenologia, frutificação, maturação, colheita.

\section{FRUIT DEVELOPMENT IN 'BENGAL' LITCHI (Litchi chinensis Sonn.)}

ABSTRACT - It was studied the fruit development in 'Bengal' litchi (Litchi chinensis Sonn.). The samples were taken weekly 35 days after anthesis until the beginning of fruit senescence. From the $77^{\text {th }}$ day after anthesis, fruits were decomposed in pericarp, aril and seed. Anthesis occurred in the first week of September. The fruit dry matter, length and diameter followed a single-sigmoid pattern. For dry matter accumulation, an initial phase, of slow growth, ended the $63^{\text {rd }}$ day after anthesis and was coincident with a period of intense fruit drop. The next phase occurred from the $63^{\text {rd }}$ to the $98^{\text {th }}$ day and showed a rapid dry matter accumulation. Until the $77^{\text {th }}$ day, the main increment in fruit dry matter was due to pericarp and seed growth. Eighty eight percent of the maximum length and $65 \%$ of the maximum diameter were reached at the end of this phase. From the $84^{\text {th }}$ until the $98^{\text {th }}$ day after anthesis, fruit growth was determined, basically, by aril. Fruit dimensions and dry matter were stabilized after the $98^{\text {th }}$ day. The commercial harvest of the fruits, characterized by the reddish color of the pericarp, occurred at the $112^{\text {th }}$ day after anthesis. Fruits at the $119^{\text {th }}$ day after anthesis were senescent.

Index terms: Litchi chinensis, inflorescence, phenology, fruit set, ripening, harvest.

\section{INTRODUÇÃO}

A lichieira (Litchi chinensis Sonn.) é uma árvore perenifólia que produz frutos de casca avermelhada e cheia de protuberâncias. $\mathrm{O}$ arilo, parte comestível que recobre a única semente marrom-escura do fruto (Menzel \& Simpson, 1994), é de cor branca, suculento, muito aromático, de alto valor nutritivo, caracterizado pelo sabor doce e levemente ácido (Taylor, 1993).

A lichia é uma drupa (Nacif, 1997) que completa seu desenvolvimento entre 11 e 16 semanas (Menzel \& Simpson, 1994). O padrão de desenvolvimento dos frutos, relatado para várias cultivares de lichia, é sigmoidal simples, com duas fases bem distintas, sendo a primeira caracterizada pelo crescimento da casca e da semente, e a segunda, por um rápido crescimento do arilo (Pereira \& Mitra, 2005; Hieke et al., 2002; Jaiswal et al., 1982).

O conhecimento das fases do desenvolvimento de frutos é essencial para auxiliar na determinação de práticas culturais, principalmente quanto ao estádio de maturação adequado para a colheita comercial (Grierson, 1995). Este trabalho teve por objetivo estudar as fases do desenvolvimento do fruto da lichieira 'Bengal'.

\section{MATERIALE MÉTODOS}

O experimento foi conduzido entre os meses de julho e dezembro de 1997, em área de pomar experimental da Universidade Federal de Viçosa, em Viçosa, Minas Gerais (2107' $\mathrm{S}, 42^{\circ} 57^{\prime} \mathrm{W}, 651 \mathrm{~m}$ de altitude), implantado em 1984, em lichieiras da cultivar Bengal, enxertadas sobre porta-enxertos originados de sementes da mesma cultivar.

A partir de julho de 1997, foram selecionadas dez lichieiras, nas quais foram marcados os ramos com inflorescências em estádios de desenvolvimento visualmente homogêneos. Procurou-se selecionar plantas visualmente homogêneas que apresentavam mais de $80 \%$ de suas brotações do tipo reprodutivo, isto é, com lançamento de inflorescências. Aos 35 dias após a antese, quando foi possível a individualização dos primeiros frutos, foram iniciadas as coletas, realizadas a cada sete dias.

Para cada amostragem, cinco ramos em frutificação foram coletados entre as dez plantas selecionadas, e os seus frutos compuseram uma amostra composta. O material proveniente do campo foi pesado para a determinação da massa da matéria fresca.

Também foram quantificados o número de frutos por inflorescência, o diâmetro e o comprimento de cada fruto e a proporção de pericarpo, arilo e semente. Os frutos foram analisados como um todo até o $70^{\underline{0}}$ dia após a antese. Após essa fase, os frutos foram separados em pericarpo, arilo e semente. Para a determinação da massa da matéria seca do fruto e de suas partes, as amostras foram acondicionadas em sacos de papel, secas em estufa com circulação forçada de ar a $65-70^{\circ} \mathrm{C}$ até massa constante ( 72 horas), submetidas à temperatura ambiente por $4 \mathrm{~h}$ e novamente pesadas.

Os dados referentes a comprimento, diâmetro, massa da matéria seca e percentagem de pericarpo, arilo e semente foram avaliados por meio de análise de regressão, e os demais, por meio de estatística descritiva, onde cada número representou a média de todos os frutos coletados em cada data de análise.

\section{RESULTADOS E DISCUSSÃO}

A emergência da inflorescência e a antese ocorreram em julho e em setembro de 1997, respectivamente. A colheita comercial do fruto (casca completamente avermelhada) ocorreu ao final de dezembro, a

\footnotetext{
(Trabalho 102/2005). Recebido: 22/06/2005. Aceito para publicação: 23/02/2006.

${ }^{2}$ Universidade Federal de Viçosa, Departamento de Fitotecnia, Av. P. H. Rolfs s/n, CEP 36570-000, Viçosa-MG. E-mail: 1salomao@ufv.br, siqueira@ufv.br, Bolsista do CNPq.

${ }^{3}$ Rua Embrapa, s/n. Cruz das Almas-BA, Brasil, CEP: 44380-000 - Caixa Postal 007. E-mail: marcio@cnpmf.embrapa.br .
} 
partir do $112^{\underline{0}}$ dia após a antese. Estas datas estão em acordo com as fases do desenvolvimento fenológico da lichieira no Hemisfério Sul, apresentadas por Menzel \& Simpson (1994).

A abscisão de frutos foi acentuada durante o mês de outubro (até o 56-0 dia após a antese), observando-se uma redução de 45 frutos por inflorescência no início do mês para 10 a 15 no fim do mês (Figura 1). $\mathrm{Na}$ época da colheita comercial (112 dias após a antese), o número médio de frutos por inflorescência estava em torno de 12, caindo para 8 no início da senescência, indicando que o pico de queda ocorre na fase inicial do desenvolvimento, embora ela continue ocorrendo durante todo o período de desenvolvimento. Revathy \& Narasimham (1997) relatam que a queda de frutos na lichieira ocorre do pegamento até o amadurecimento, com pico no primeiro mês deste período, havendo,

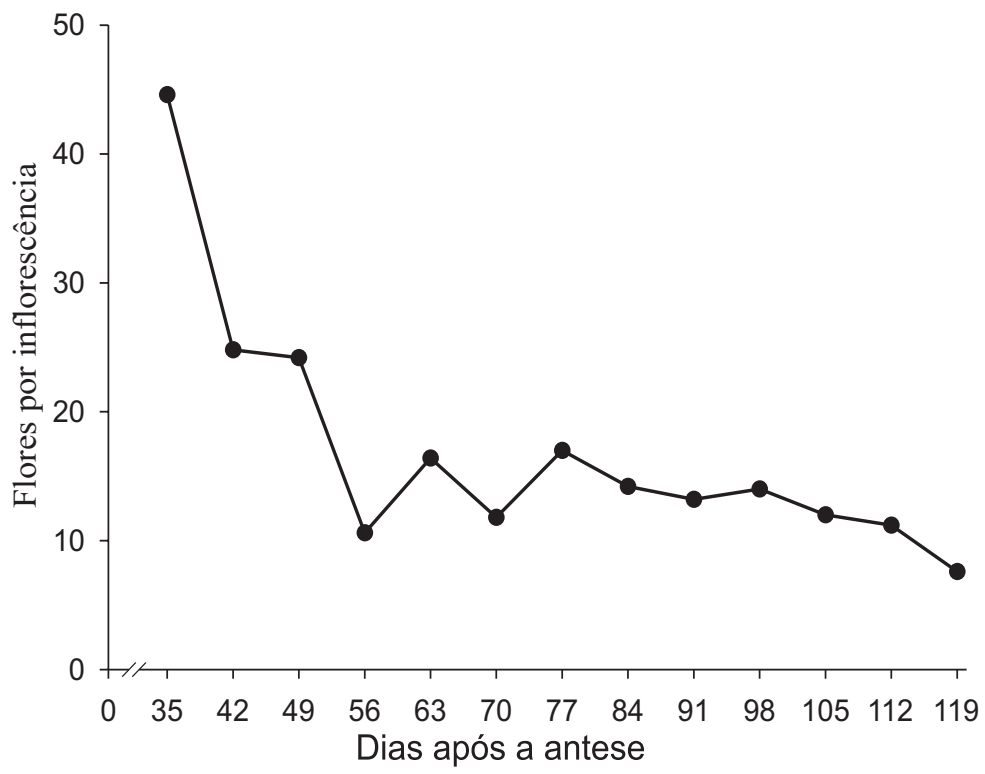

FIGURA 1 - Número de frutos por inflorescência da lichieira 'Bengal'. A colheita comercial dos frutos ocorreu a partir de 112 dias após a antese.

— Comprimento $\hat{\mathrm{Y}}=40,9718 /\left(1+\mathrm{e}^{-(\mathrm{x}-49,6037) / 14,0781}\right) \mathrm{R}^{2}=0,9773$

............ Diâmetro $\hat{\mathrm{Y}}=36,0740 /\left(1+\mathrm{e}^{-(\mathrm{x}-69,5307) / 13,0208}\right) \mathrm{R}^{2}=0,9690$

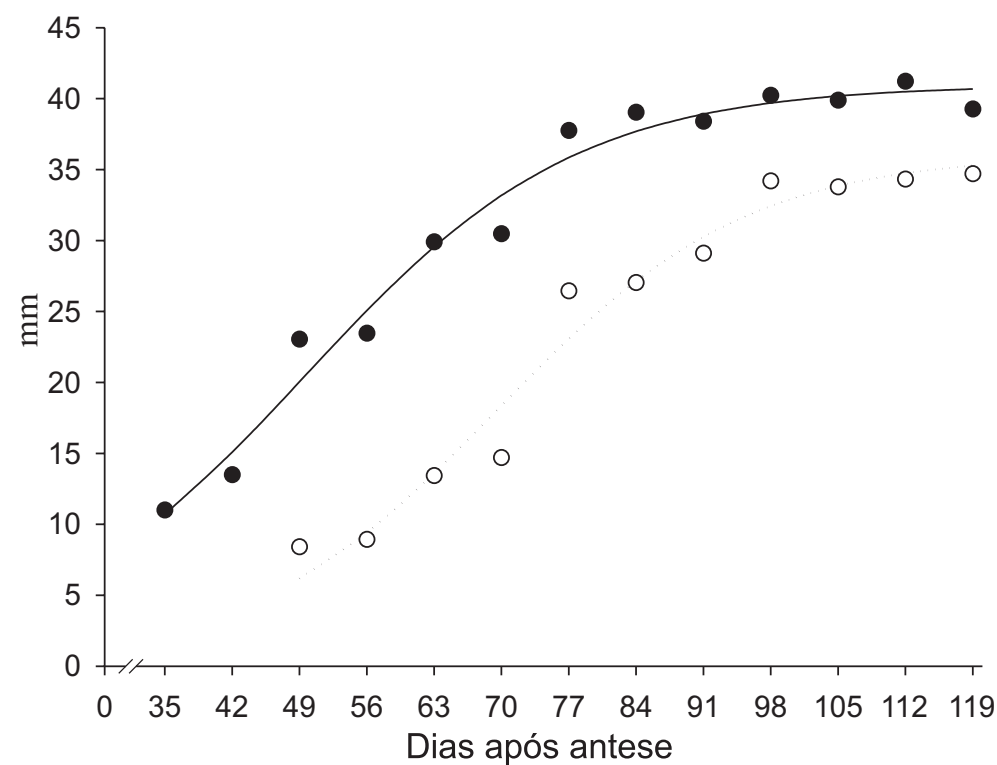

FIGURA 2 - Comprimento e diâmetro, em mm, do fruto da lichieira 'Bengal'. A colheita comercial dos frutos ocorreu a partir de 112 dias após a antese. portanto, concordância dos resultados deste trabalho com os obtidos pelos autores citados. A queda de flores e frutos pode estar relacionada à menor presença de feixes vasculares nos pedicelos, o que reduziria $\mathrm{a}$ chegada de nutrientes, fotoassimilados e reguladores de crescimento para o fruto, impedindo seu desenvolvimento (Zhang, 1997).

O desenvolvimento dos frutos em comprimento ocorreu de forma acelerada até meados de novembro, em torno de 77 dias após a antese (Figura 2), passando de $11 \mathrm{~mm}$ para $36 \mathrm{~mm}$ (aumento de 3,3 vezes). A partir de meados de novembro, observaram-se pequenas alterações no desenvolvimento. $\mathrm{O}$ aumento do comprimento dos frutos da antese até o $77^{0}$ dia foi devido basicamente ao crescimento do pericarpo e da semente, pois, até esse momento, a formação do arilo era incipiente (Figura 3).

$$
\begin{aligned}
& \rightarrow \nabla-- \text { Fruto } \hat{\mathrm{Y}}=5,3770 /\left(1+\mathrm{e}^{-(\mathrm{x}-80,6874) / 8,8102}\right) \quad \mathrm{R}^{2}=0,9681 \\
& \longrightarrow \text { - Pericarpo } \\
& \cdots \cdots \cdots \cdot \text {-.... Arilo } \\
& --\nabla-- \text { Semente }
\end{aligned}
$$

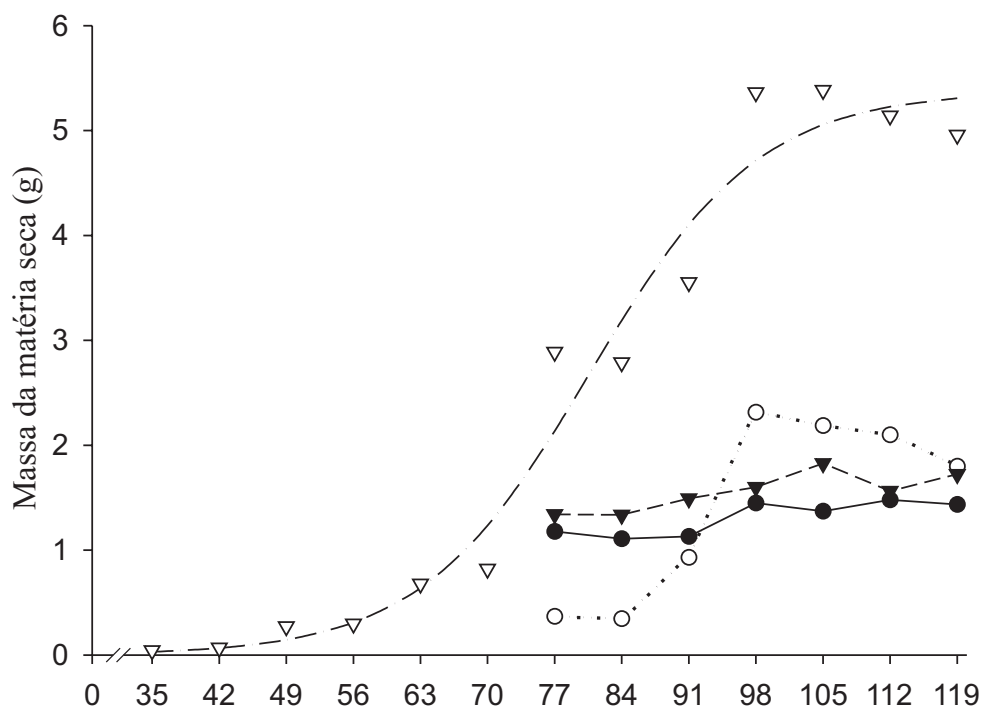

FIGURA 3 - Massa da materias após a a antese do fruto inteiro, pericarpo, arilo e semente da lichieira 'Bengal'. A colheita comercial dos frutos ocorreu a partir de 112 dias após a antese.

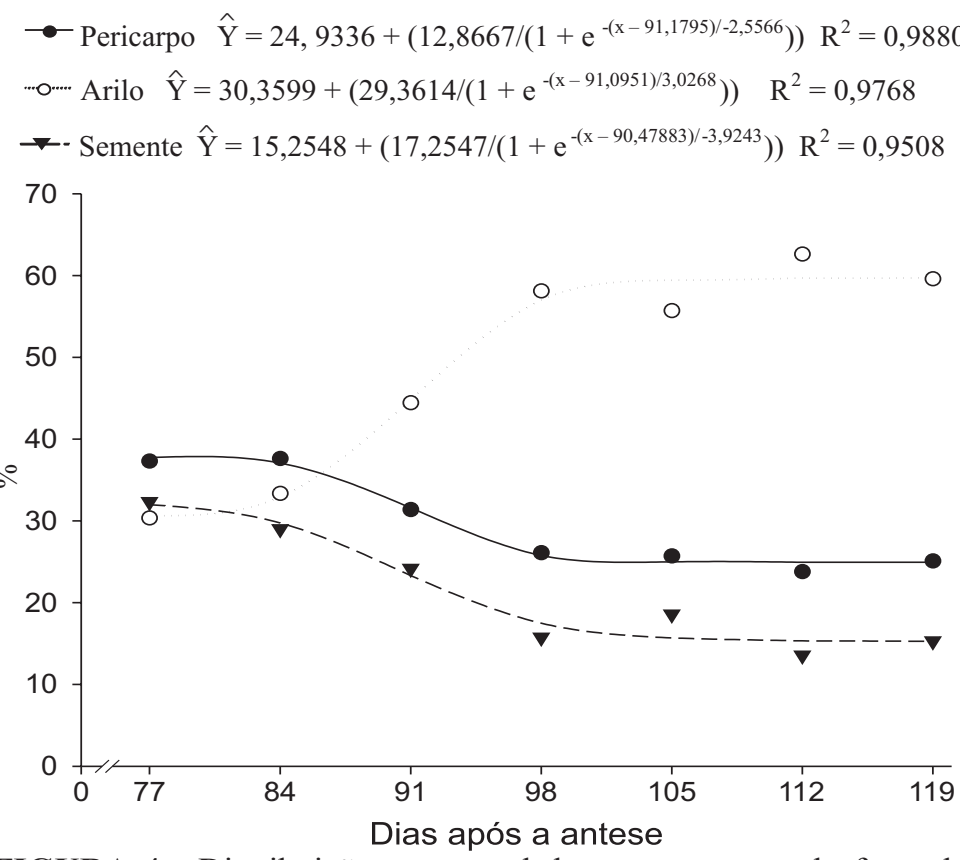

FIGURA 4 - Distribuição percentual dos componentes do fruto da lichieira 'Bengal', com base na massa da matéria fresca. A colheita comercial dos frutos ocorreu a partir de 112 dias após a antese. 
Por outro lado, o desenvolvimento em diâmetro prolongou-se até o início de dezembro (98ํㅡㅁ dia (Figura 2), passando de $6 \mathrm{~mm}$ para 32 $\mathrm{mm}$, aumentando, portanto, 5,2 vezes. A partir do $98^{\circ} \mathrm{dia}$, as dimensões do fruto estabilizaram-se. $\mathrm{O}$ aumento do diâmetro foi influenciado principalmente pelo crescimento do arilo (Figura 4).

Para o acúmulo de matéria seca do fruto, foi ajustado um modelo do tipo sigmoidal simples (Figura 3), com três fases características no desenvolvimento. Na primeira, houve um período de acúmulo lento de massa (até o $63^{\underline{0}}$ dia), na segunda, um crescimento mais rápido (do $63^{0}$ até o $98^{0}$ dia) e na terceira, um período de desaceleração (do $98^{0}$ dia em diante). A forma da curva, a duração e a manifestação de cada período de crescimento variam de acordo com a cultivar e as condições ambientais (Coombe, 1976).

O lento acúmulo de matéria seca na primeira fase, que perdurou durante todo o mês de outubro (Figura 3), provavelmente ocorreu porque, nesse período, o número de frutos por inflorescência ainda era elevado (Figura 1), havendo, portanto, maior competição entre eles.

A separação dos frutos em pericarpo, arilo e semente só foi realizada a partir do $77^{0}$ dia. Pela análise da Figura 3, observa-se que, nesse período, pericarpo e semente, juntos, representavam $87 \%$ da massa da matéria seca do fruto, e este atingiu $88 \%$ e $65 \%$ de seu comprimento e diâmetro máximos, respectivamente (Figura 2). Comportamento semelhante também foi observado por Nacif (1997), pelo qual se justifica a forma alongada do fruto nesta fase.

A constatação de um padrão sigmoidal simples para o acúmulo de matéria seca, descrito neste trabalho, está de acordo com o que foi verificado por outros autores, para várias cultivares de lichieira (Huang \& Xu, 1983; Paull et al., 1984; Vieira et al., 1996; Nacif, 1997). Nos resultados apresentados por Paull et al. (1984) e Nacif(1997), verificase a existência de uma fase curta de detenção do crescimento, semelhante àquela encontrada neste trabalho, que ocorreu entre o $77^{0}$ e o $84^{0}$ dia após a antese (ver dados observados na Figura 3). Nessa fase, observase uma tendência de estabilização no crescimento do pericarpo e da semente, e início do crescimento do arilo, o que poderia permitir a interpretação de que algumas cultivares de lichia apresentam padrão de desenvolvimento sigmoidal duplo.

O incremento de matéria seca no fruto cessou a partir do $98^{0}$ dia após a antese (Figura 3). A partir do $98^{0}$ dia após a antese, houve perda de matéria seca do arilo, gerando perda no fruto inteiro (Figura 3, dados observados).

Vieira et al. (1996) observaram que os frutos da cultivar Brewster estavam com coloração vermelha e maduros a partir do $89^{0}$ dia após o florescimento, o que corresponderia, no presente trabalho, a frutos com aproximadamente 112 dias após a antese. Os autores mencionados

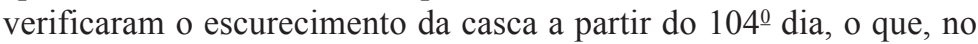
presente trabalho, foi observado no $119^{0} \mathrm{dia}$, indicando o início da senescência.

Tomando por base a massa da matéria fresca do fruto aos 77 dias, a proporção de pericarpo, semente e arilo era de $37,8 \%, 32,0 \%$ e $30,6 \%$, respectivamente (Figura 4). No período da colheita, aos 112 dias, a proporção de arilo elevou-se para $59,7 \%$ e a de pericarpo e semente reduziu-se para $24,9 \%$ e 15,3\%, respectivamente. A proporção de arilo, parte comestível do fruto, aproximou-se das observações de $60 \%$ de Vieira et al. (1996), superou o resultado de cerca de $45 \%$ obtido por Nacif (1997) e foi inferior aos 78\% apresentados por Martins (1992) para 'Brewster'.

\section{CONCLUSÕES}

Nas condições do experimento, para a cultivar 'Bengal', conclui-se que:
1. O número de frutos por inflorescência caiu ao longo do desenvolvimento dos frutos. O período de maior queda de frutos ocorreu durante o mês de outubro, entre 35 e 56 dias após a antese, estabilizandose em 10 a 15 frutos por inflorescência.

2. O fruto apresentou um padrão sigmoidal simples para o acúmulo de matéria seca. Uma fase inicial, de lento crescimento, coincidiu com o período de queda natural de frutos. A fase de rápido acúmulo de matéria seca correspondeu, inicialmente, ao crescimento do pericarpo e da semente e, posteriormente, ao crescimento do arilo. As dimensões e o incremento de matéria seca do fruto estabilizam-se a partir do $98^{0}$ dia após a antese.

3. A colheita comercial dos frutos ocorreu a partir do $112^{0}$ dia após a antese, com o pericarpo completamente avermelhado. Verificouse um quadro senescente nos frutos a partir do $119^{0}$ dia após a antese.

\section{REFERÊNCIAS}

COOMBE, B.F. The development of fleshy fruits. Annual Review of Plant Physiology, Palo Alto, v.27, p.507-28, 1976.

GRIERSON, W. Fruit development, maturation, and ripening. In: PESSARAKLI, M. (Ed.). Handbook of plant and crop physiology. New York: Marcel Dekker, 1995. p.419-35.

HIEKE, S.; MENZEL, C.M.; LUDDERS, P. Effects of leaf, shoot and fruit development on photosynthesis of lychee trees (litchi chinensis). Tree Physiology, Victoria, v.22, n.13, p.955-961, 2002.

HUANG, H.; XU, J. The developmental patterns of fruit tissues and their correlative relationships in Litchi chinensis Sonn. Scientia Horticulturae, Amsterdam, v.19, n.3/4, p.335-42, 1983.

JAISWAL, B.P.; JHA, A.K.; SAH, N.L.; PRASAD, U.S. Characteristics of fruit growth and development in litchi cultivars. Indian Journal of-Plant Physiology, New Delhi, v.25, n.4, p. 411-414, 1982.

MARTINS, A.B.G. Cultura da lichia. In: DONADIO, L.C.; MENDES, A.B.G.; VALENTE, J.P.(Ed.). Fruticultura tropical. São Paulo: FUNEP, 1992.p. 113-26.

MENZEL, C. M.; SIMPSON, D. R. Lychee. In: SCHAFFER, B.; ANDERSEN, P. C. (Ed.). Handbook of environmental physiology of fruit crops. Boca Raton: CRC, 1994. v.2, p.123-45.

NACIF, S.R. Aspectos anatômicos e fisiológicos do desenvolvimento do fruto de Litchi chinensis Sonn. cv. Brewster (lichia SAPINDACEAE). 1997. 89 f. Tese (Doutorado em Ciências Biológicas) - Universidade Estadual Paulista, Rio Claro, SP: UNESP, 1997.

PAULL, R. E.; CHEN, N. J.; DEPUTY, J. Litchi growth and compositional changes during fruit development. Journal of the American Society for Horticultural Science, Alexandria, v.109, n.6, p.817-21, 1984.

PEREIRA, L.S.; MITRA, S.K. Studies on fruit growth and development of litchi cultivars Bombai, China, Deshi and Early Large Red. Horticultural Journal, Mohanpu, v.17, n.2 p.115-124, 2004.

REVATHY, J.; NARASIMHAM, P. Litchi (Litchi chinensis Sonn.) fruit: influence of pre- and post-harvest factors on storage life and quality for export trade - a critical appraisal. Journal of Food Science and Technology, Mysore, v.34, n.1, p.1-19, 1997.

TAYLOR, J.E. Exotics. In: SEYMOUR, G.B.; TAYLOR, J.E.; TUCKER, G.A. Biochemistry of fruit ripening. London: Chapman \& Hall, 1993.p.151-187.

VIEIRA, G.; FINGER, F.L.; AGNES, E.L. Growth and development of litchi fruit cv. Brewster. Bragantia, Campinas, v.55, n.2, p.325-8, 1996.

ZHANG, D.P. The relationship between structures of fruit stalks and fruit dropping in litchi. Acta Horticulturae Sinica, Beijing, v.24, n.2,p.105-10, 1997. 